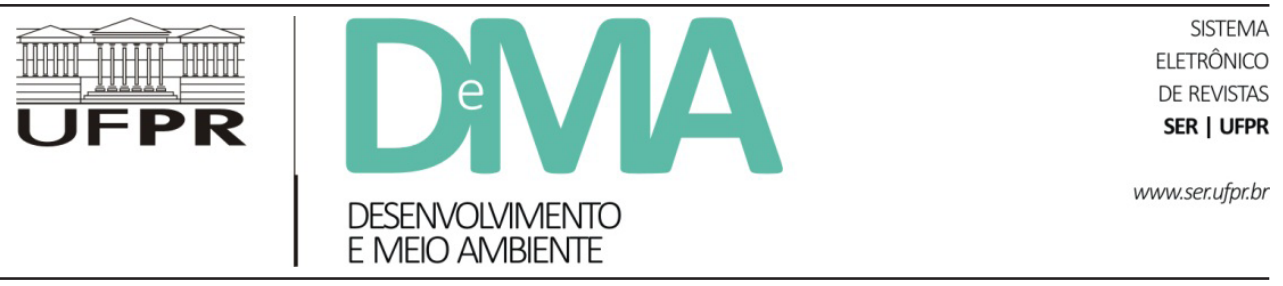

\title{
Vulnerabilização socioambiental de comunidades tradicionais no Complexo Industrial Portuário de Suape
}

\section{Socioenvironmental Increasing Vulnerability of Traditional Communities in the South Coast of Pernambuco}

\author{
Stevam Gabriel ALVES ${ }^{1 *}$, Mariana Olívia Santana dos SANTOS$^{2}$, Idê Gomes Dantas GURGEL², Solange \\ Laurentino dos SANTOS ${ }^{2}$ \\ ${ }^{1}$ Programa de Desenvolvimento e Meio Ambiente, Universidade Federal de Pernambuco (UFPE), Recife, PE, Brasil. \\ ${ }^{2}$ Programa de Pós-Graduação em Saúde Pública, Centro de Pesquisa Aggeu Magalhães, Fundação Oswaldo Cruz, Recife, PE, Brasil. \\ *E-mail de contato: stevam_gabriel@hotmail.com
}

Artigo recebido em 16 de dezembro de 2015, versão final aceita em 21 de agosto de 2016.

RESUMO: Nos últimos anos, as obras de expansão do Complexo Industrial Portuário de Suape (CIPS) foram responsáveis por uma série de injustiças socioambientais que se materializam em um profundo processo de descaracterização socioambiental das comunidades tradicionais localizadas no território ocupado por novas indústrias. Essas injustiças proporcionam situações de vulnerabilização socioambiental por meio das atividades produtivas de dois grandes empreendimentos: a Refinaria Abreu e Lima e o Estaleiro Atlântico Sul. Este artigo teve como objetivo identificar os processos de vulnerabilização socioambiental que ocorrem nas comunidades Engenho Mercês e Ilha de Tatuoca, onde estão localizados os empreendimentos citados. Os procedimentos metodológicos utilizados foram: I) visitas de campo, II) entrevistas semiestruturadas; III) técnica de saturação teórica dos dados; IV) pesquisa bibliográfica; e V) registros fotográficos. Como resultado, identificaram-se algumas situações de vulnerabilização socioambiental advindas das atividades industriais, tais como: poluições hídrica, sonora e atmosférica; diminuição dos recursos naturais e processos de desterritorialização. Dessa forma, torna-se evidente que a expansão do CIPS por meio da chegada de novas indústrias é a responsável direta pelos processos de vulnerabilização que atingem os moradores das comunidades estudadas, interferindo diretamente nas relações entre sociedade e meio ambiente.

Palavras-chave: degradação ambiental; injustiças socioambientais; complexo industrial portuário de Suape.

ABSTRACT: In recent years, the works of expansion of Port Industrial Complex of Suape (Complexo Industrial Portuário de Suape - CIPS) were responsible for a series of social and environmental injustices, which were manifested in a deep process of decharacterization of traditional communities located in the territory occupied by new industries. Those injustices have provided situations of socioenvironmental vulnerability through the productive activities of two major projects: The Abreu e Lima Refinery and the South Atlantic Shipyard. The aim of this article 
was to identify which socioenvironmental vulnerability processes are occurring in the communities of study Engenho Mercês and Ilha de Tatuoca, which were the locations chosen for construction of these companies. The methodological procedures used were: I) field visits II) semi-structured interviews; III) theoretical saturation technique of data; IV) bibliographic research; V) photographic registry. As a result, the survey identified some situations of social and environmental vulnerability resulting from industrial activities, such as: water, noise and air pollution; reduction of natural resources and dispossession processes. It is concluded that the expansion of CIPS, through the arrival of new industries, is directly responsible for the process of vulnerability reaching residents of the communities studied, interfering directly in the relations between society and the environment.

Keywords: environmental degradation; port industrial complex of Suape; socioenvironmental injustices.

\section{Introdução}

O Brasil possui uma grande diversidade sociocultural que se expressa pelas comunidades tradicionais, por meio da pluralidade de etnias, línguas, comportamentos, saberes e modos de vida (Silva, 2007). Para o autor, a principal questão para essas comunidades é o acesso ao território, pois é nele onde se dão suas práticas culturais e socioambientais, como: o manejo dos recursos naturais, os sistemas produtivos, os modos tradicionais de distribuição e consumo da produção, a endoculturação, a reprodução dos saberes tradicionais, os acontecimentos e/ou fatos históricos que compõem a identidade de um grupo.

Outro ponto que caracteriza a singularidade desses povos são seus processos produtivos marcados pela economia de subsistência, na qual a produção é determinada por questões ligadas às necessidades versus possibilidades. É importante destacar as dificuldades enfrentadas por esses povos nos campos político e econômico, sobretudo no que diz respeito ao reconhecimento de suas formas de organização social (Silva, 2007).

As comunidades tradicionais são definidas pelo uso sustentável da terra, pelo destino da sua produção e pelo seu vínculo territorial, incluindo sua situação fundiária, pela importância que os ciclos naturais têm nas suas práticas produtivas, pelo uso que fazem dos recursos renováveis e pe- las práticas de uso comunitário dos mesmos, pelo seu conhecimento profundo do ecossistema onde vivem, pelo uso de tecnologias de baixo impacto ambiental, por sua organização social, na qual a família representa um papel importante, e também por suas expressões culturais e pelas inter-relações com outros grupos da região (Little, 2005).

Pelo fato de desenvolverem processos históricos diferenciados em relação a outros segmentos da sociedade brasileira, ocasionou-se, ao mesmo tempo, uma riqueza sociocultural e uma invisibilidade perante a sociedade moderna e as políticas públicas de modo geral. Essa invisibilidade dos povos tradicionais acarreta a ausência de políticas públicas em questões primordiais, como no acesso à terra, à saúde e à educação, tornando-os vulnerabilizados e ao mesmo tempo impedidos de reproduzir suas práticas culturais, sociais e econômicas (Rapkiewicz et al., 2015).

Um grande problema enfrentado pelos povos tradicionais atualmente é a sobreposição de territórios. Devido à vulnerabilidade desses povos, grandes projetos homogeneizadores de espaço, como complexos industriais, portos, hidroelétricas, minerodutos, dentre outros, se instalam nos territórios já habitados e destinam todo passivo de suas atividades produtivas às comunidades do seu entorno, interferindo diretamente nos seus modos de vida. Segundo Porto (2011), a dimensão central da vulnerabilidade decorre das iniquidades sociais 
agravadas por processos econômicos e políticas públicas que desprezam o cuidado para com as populações mais impactadas.

Ligado ao conceito de vulnerabilidade há o de vulneração, comumente utilizados como sinônimos, mas que apresentam uma sensível diferença: vulnerabilidade se refere à condição de quem pode ser ferido, ao passo que vulneração se refere especificamente à condição de quem já está ferido (Schramm, 2012). Dito de forma mais geral, no primeiro caso estamos em presença de uma potencialidade compartilhada pelo universo de todos os seres vivos. No segundo, de algo que afeta determinados seres vivos específicos e que é necessariamente universalizável, pois todos os seres vivos são por essência vulneráveis devido à condição de finitude e mortalidade que os caracteriza, ao passo que somente alguns são de fato afetados ou vulnerados (Schramm, 2012).

A vulnerabilização à qual se refere o trabalho é o processo que uma população sofre ao passar de uma condição de vulnerabilidade para a de vulnerada. Para Acselrad (2010a), populações vulnerabilizadas são aquelas que foram destituídas de seus direitos, principalmente por meio de injustiças socioambientais.

A injustiça ambiental é definida como:

[...] A condição de existência coletiva própria a sociedades desiguais, onde operam mecanismos sociopolíticos que destinam a maior carga dos danos ambientais do desenvolvimento a grupos sociais de trabalhadores, populações de baixa renda, segmentos raciais discriminados, parcelas marginalizadas e mais vulneráveis da cidadania (Acselrad et al., 2004, p. 9).
A injustiça ambiental resulta da lógica perversa de um sistema de produção que destrói ecossistemas; que contamina o ar, o solo e os corpos hídricos e que direciona toda essa carga de danos socioambientais às populações tradicionais ou vulneráveis, que são excluídas pelos grandes projetos de desenvolvimento e que têm, com esses impactos, uma drástica alteração na sua qualidade de vida (Acselrad, 2002).

A perda de seus lares, a presença de substâncias cancerígenas presentes nos poluentes e a ausência de políticas públicas de saneamento, educação, saúde e infraestrutura são exemplos que configuram as manifestações visíveis de um modelo fundado na injustiça estrutural e na irresponsabilidade ambiental de empresas e governos. Apesar dessas evidências, ainda assim, são negadas por seus responsáveis, que afirmam não haver relação entre as atividades produtivas, as decisões políticas e as consequências sobre os afetados (Moura, 2010).

As situações de desigualdades socioambientais promovidas pelo capital e pelos atores do Estado geram situações de vulnerabilidade socioambiental, entendida como uma sobreposição espacial entre grupos populacionais pobres, discriminados e com alta privação (vulnerabilidade social), que vivem ou circulam em áreas de risco ou de degradação ambiental (vulnerabilidade ambiental). Essas regiões onde as populações pobres e discriminadas são forçadas a viver são entendidas como "zonas de sacrifício"" (Bullard, 1996 apud Cartier et al., 2009). Dessa forma, pode-se afirmar que o conceito de vulnerabilidade socioambiental está associado a uma exposição diferenciada frente aos riscos e designa a maior susceptibilidade

\footnotetext{
1 A expressão "zonas de sacrifício" é utilizada para designar localidades em que se observa uma superposição de empreendimentos e instalações responsáveis por danos e riscos ambientais. Ela tende a ser aplicada a áreas de moradia de populações de baixa renda, onde o valor da terra relativamente mais baixo e o menor acesso dos moradores aos processos decisórios favorecem escolhas de localização que concentram, nestas áreas, instalações perigosas (Viégas, 2006).
} 
de certos grupos populacionais preverem, enfrentarem ou sofrerem as consequências decorrentes de algum tipo particular de perigo (Porto, 2007).

Dessa forma, o presente trabalho tem como objetivo identificar os processos de vulnerabilização socioambiental que ocorrem nas comunidades de Engenho Mercês e Ilha de Tatuoca, localizadas no interior do Complexo Industrial Portuário de Suape (CIPS), litoral sul de Pernambuco.

\section{Caracterização da área de estudo e procedimentos metodológicos}

\subsection{Caracterização do Complexo Industrial Portuário de Suape}

Devido ao crescimento econômico de Pernambuco em meados do século XX, surgiu a necessidade de uma estrutura portuária maior e mais moderna, pois, se não houvesse reformas de infraestrutura, surgiriam empecilhos ao crescimento econômico do Estado. Assim, surge o Complexo Industrial Portuário de Suape, na década de 1970, a partir do novo conceito de integração porto-industrial existente nos portos de Marseille, na França, e Kashima, no Japão (Trevas, 2005). O objetivo desse empreendimento foi agregar áreas extensas para a implantação das indústrias e serviços de apoio marítimo.

O sucesso para a consolidação desse complexo portuário e industrial aponta para uma concepção audaciosa em sua época, que aliava a instalação de grandes indústrias em seu território, como petrolífe- ra, petroquímica, siderúrgica e naval, a uma moderna superestrutura portuária, permitindo uma interconexão entre terra e mar fundamentada pelo movimento de litoralização da indústria (Alves, 2011).

Esses pontos elevaram o CIPS a uma condição de potencial concentrador de cargas regional, colocando-se em condições de competição com qualquer outro porto da Região Nordeste. Contudo, nos dias atuais, Suape não tem apenas uma importância regional, mas nacional, devido principalmente aos grandes investimentos que atrai (Alves, 2011).

Os benefícios de um Complexo Industrial Portuário do ponto de vista financeiro foram inúmeros, principalmente por conta da chegada das grandes multinacionais. Contudo, é importante salientar que essas benesses econômicas são destinadas em sua maioria para a elite empresarial pernambucana. Um exemplo que reflete essa situação é o município de Ipojuca (um dos municípios que sedia o CIPS), detentor de um dos maiores PIBs do Brasil, mas que, ao mesmo tempo, possui uma das maiores taxas de analfabetismo nacional (Santos, 2011). Dessa forma, é evidente que o progresso produzido pelo CIPS não é destinado para toda a população pernambucana, mas para uma pequena parcela.

\subsection{Procedimentos metodológicos}

Para análise dos processos de vulnerabilização socioambiental, foram utilizados os discursos dos moradores sobre as interferências dos empreendimentos in loco e a observação direta ${ }^{2}$ do pesquisador em duas comunidades inseridas no Complexo Industrial Portuário de Suape. São essas: Engenho Mercês

\footnotetext{
2 A expressão "zonas de sacrifício" é utilizada para designar localidades em que se observa uma superposição de empreendimentos e instalações responsáveis por danos e riscos ambientais. Ela tende a ser aplicada a áreas de moradia de populações de baixa renda, onde o valor da terra relativamente mais baixo e o menor acesso dos moradores aos processos decisórios favorecem escolhas de localização que concentram, nestas áreas, instalações perigosas (Viégas, 2006).
} 
e Tatuoca (Figura 1), onde estão localizados dois grandes empreendimentos, respectivamente: Refinaria Abreu e Lima e o Estaleiro Atlântico Sul, que desde a fase de implantação vêm gerando passivos socioambientais nas comunidades (Santos, 2011).

Realizou-se pesquisa de campo que possibilitou: I) conhecer a realidade vivida pelos moradores das comunidades; II) registros fotográficos dos processos de vulnerabilização socioambientais sofridos pela população; III) a realização de entrevistas.
Os critérios de seleção dos entrevistados foram: ser maior de 18 anos; morador nativo ou residente por mais de dez anos na região; e moradia próxima à área industrial. As perguntas realizadas aos entrevistados foram referentes à mudança de vida antes e depois da chegada das empresas na comunidade; utilização dos recursos naturais; emissão de poluentes na comunidade; remoção dos moradores; e assistência aos moradores pelo CIPS.

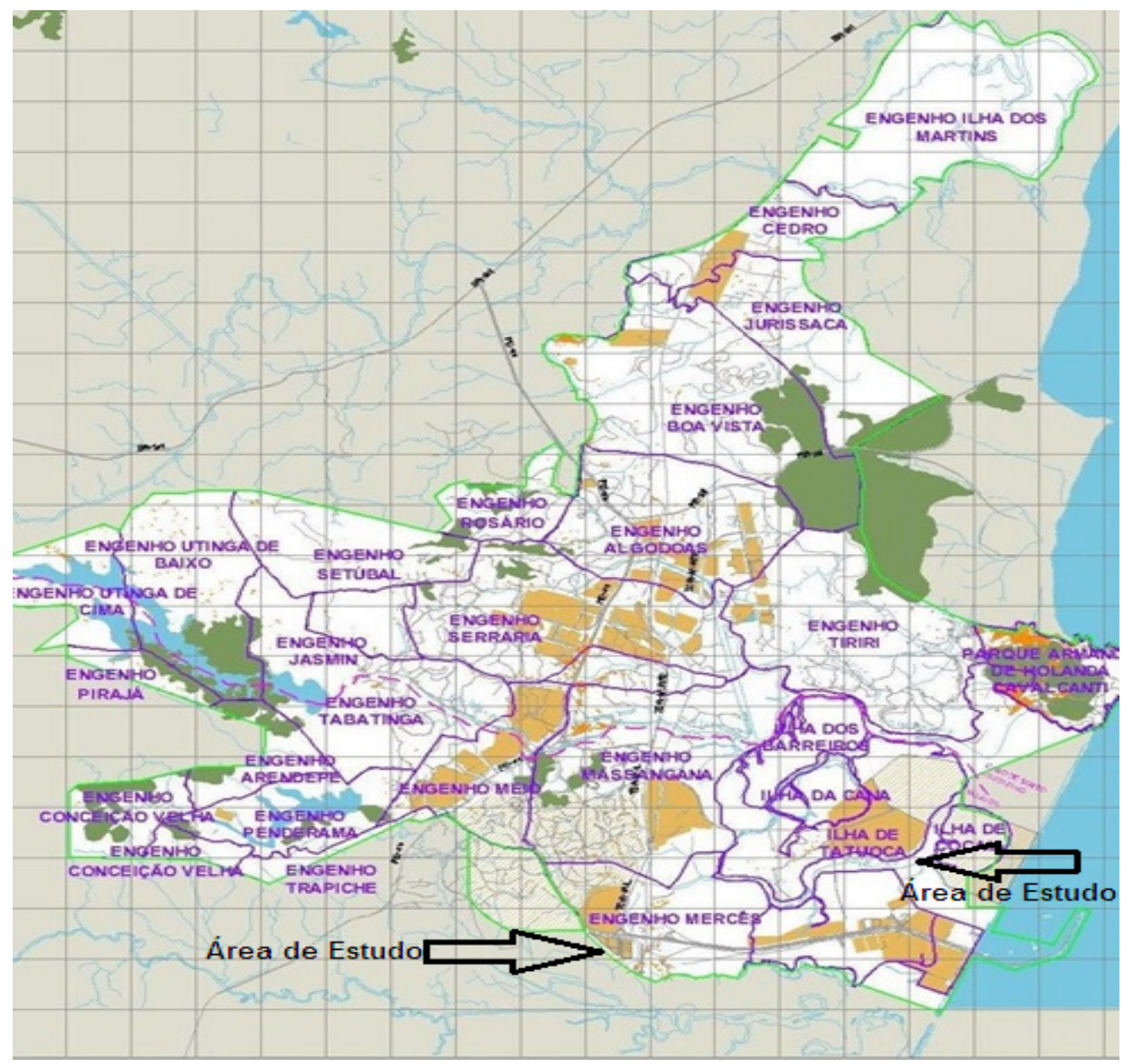

FIGURA 1 - Localização da área de Estudo no CIPS.

FONTE: Adaptado do RIMA da RNEST, 2005. (Pérez \& Gonçalves, 2012. 
Para o fechamento da amostra, foi utilizada a técnica de saturação teórica de dados, ou seja, o tamanho da amostra dependerá do término de novas informações e o alcance da redundância nos dados obtidos (Minayo, 2008). Dessa forma, ao todo foram realizadas 20 entrevistas gravadas e autorizadas por meio do Termo de Consentimento Livre e Esclarecido - TCLE.

$\mathrm{O}$ artigo foi desenvolvido em parceria com o projeto "Vulnerabilidade Socioambiental relacionada à exposição química nos territórios de desenvolvimento das cadeias produtivas de petróleo e das consumidoras de agrotóxicos", aprovado pelo Comitê de Ética e Pesquisa do Centro de Pesquisas Aggeu Magalhães/FIOCRUZ-PE, sob o registro CAEE de $n^{\circ}$ 44507115.5.0000.5190. Salienta-se que as identidades dos entrevistados foram preservadas, sendo mencionado apenas o número da entrevista.

A pesquisa documental foi realizada por meio de artigos disponibilizados na internet, dissertações e teses, sendo de fundamental importância para o entendimento de alguns conceitos-chave. Além disso, o EIA ${ }^{3} /$ RIMA $^{4}$ da Refinaria Abreu e Lima e Estaleiro Atlântico Sul e o banco de dados da $\mathrm{CPRH}^{5}$ foram de grande utilidade para o conhecimento das atividades produtivas desses empreendimentos que estão localizados nas comunidades estudadas.

O método de análise utilizado para o levantamento dos processos de vulnerabilização socioambiental junto aos moradores da comunidade foi a Análise Crítica do Discurso. Este método é uma forma de ciência crítica que foi concebida como ciência social destinada a identificar os problemas que as pessoas enfrentam em decorrência de formas particulares da vida social (Fairclough, 2003).

\section{Impactos socioambientais advindos do Complexo Industrial Portuário de Suape}

A expansão sem planejamento e o crescimento econômico baseado em um modelo capitalista não inclusivo, com devastação ambiental e indústrias sujas, continuam sendo as marcas do Complexo Industrial Portuário de Suape. A atração por indústrias altamente agressoras ao meio ambiente, aliada a perdas e injustiças cometidas, como: violações dos direitos fundiários, alteração do ecossistema marinho, emissões de efluentes industriais e poluentes atmosféricos, desestruturação de relações simbólicas da população com o lugar, modificação no perfil de saúde das populações, e ausência de políticas públicas que possibilitem sua reprodução social, são as principais causas de vulnerabilização das comunidades localizadas no interior do CIPS (Costa, 2014; Associação de Geógrafos Brasileiros, 2011).

A vulnerabilização é pautada neste estudo como a nuance que permite dar luz e precisão ao reconhecimento de povos e comunidades que se encontram em processo ativo de violência e discriminação, por meio dos impactos de grandes empreendimentos e concessões estatais que percebem esses povos como obstáculos arcaicos ao progresso (Porto et al., 2013). Como exemplos desse processo, serão abordadas duas situações em comunidades tradicionais que se inserem nesse contexto.

\subsection{A Comunidade Engenho Mercês}

A comunidade Engenho Mercês está localizada na Zona Industrial Portuária do CIPS no município

\footnotetext{
3 Estudo de Impacto Ambiental.

4 Relatório de Impacto Ambiental.

5 Companhia Pernambucana de Recursos Hídricos, também conhecida como Agência Estadual de Meio Ambiente.
} 
de Ipojuca, sendo cortada pelas principais vias de acesso à área do porto. Grandes empreendimentos, como a Refinaria Abreu e Lima e a Petroquímica, estão situados nas terras desse antigo engenho e, por tal motivo, os moradores da comunidade serão retirados para instalação de novos empreendimentos na localidade (Silveira, 2010).

Segundo relatos dos moradores, a comunidade possui aproximadamente 100 famílias, que não vivem mais exclusivamente da agricultura e da pesca por conta das interferências das indústrias localizadas no interior da comunidade (Figura 2), resultando na busca por outros tipos de trabalho, na construção civil, predominantemente. Entretanto, algumas famílias ainda têm suas atividades baseadas na criação de animais de pequeno porte, na agricultura de subsistência (roça de mandioca, feijão, fruteiras), na utilização dos manguezais e do estuário do rio Tatuoca para a pesca, tendo esses espaços como valor de uso. A ampliação do polo

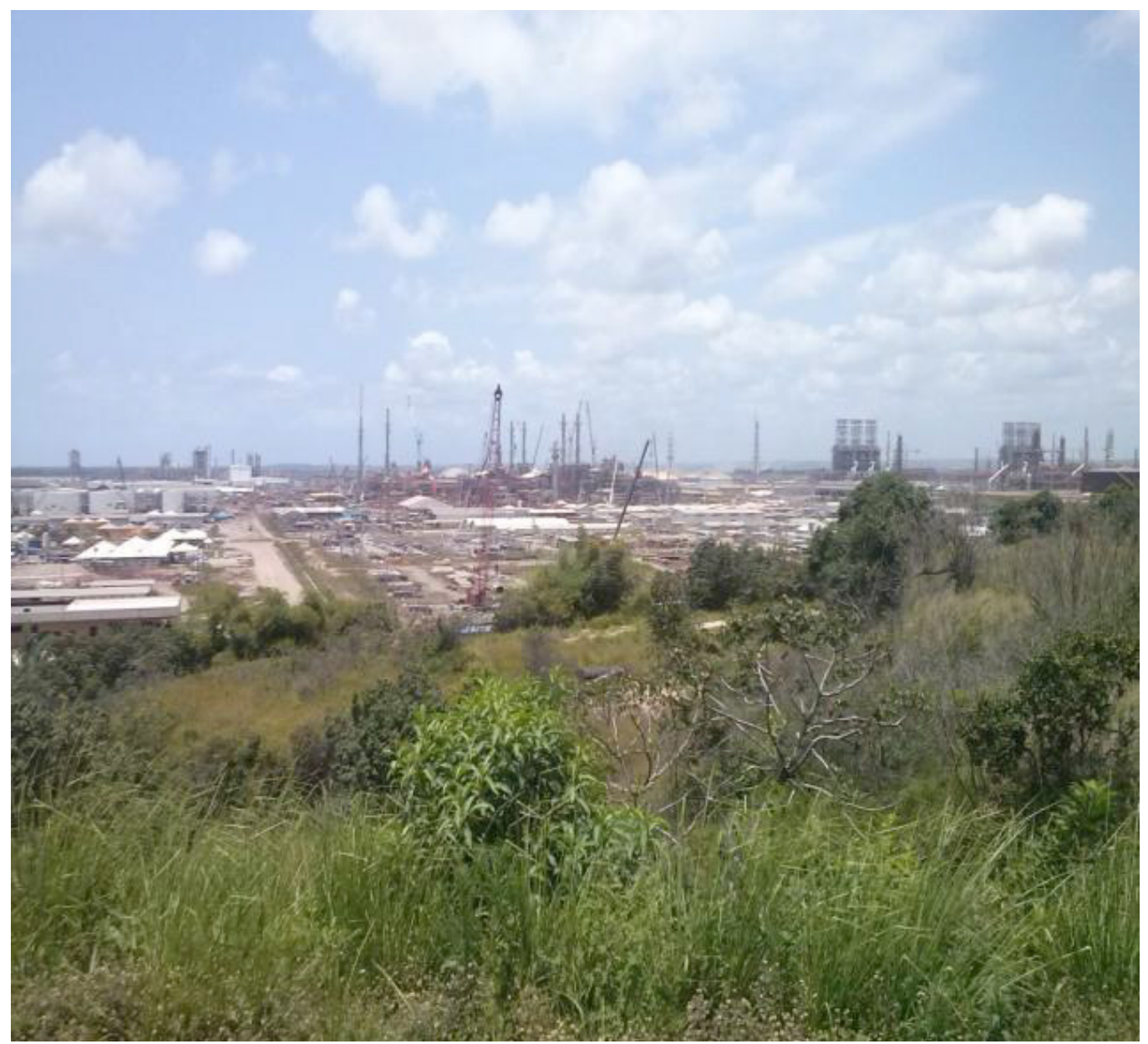

FIGURA 2 - Refinaria Abreu e Lima. Distrito Industrial Portuário de Suape. FOTO: Stevam Gabriel, setembro de 2013. 
industrial vem causando a destruição da fauna e da flora, seja por meio de processos diretos, como o desmatamento, ou indiretos, como a poluição das águas e do solo, afetando diretamente o ecossistema local. Essas interferências são geradas em prol da instalação e da operação de novas indústrias, uma vez que a população dessa comunidade é um grupo vulnerável no processo de dominação do capital sobre a terra e o campo (Rossini, 2009; Alves, 2014).

$\mathrm{O}$ discurso dos entrevistados sobre a percepção relacionada aos impactos socioambientais decorrentes das obras de implantação e expansão do CIPS aponta várias situações de vulnerabilidades socioambientais, por vezes, irreversíveis. As falas a seguir corroboram essa afirmativa:

Entrevistado 1. Eles tá pra negociar o terreno, o valor que colocaram foi 65 mil, por isso que não saí, aqui tenho meu terreno, minhas fruteiras. E onde vou comprar uma casa com 65 mil. Pra mim vale mais de 100 mil porque é onde tô vivendo, eles têm que ver a situação da pessoa (Aposentado, morador nativo da comunidade há 65 anos).

Entrevistado 2. Meu projeto é sair mesmo, porque vai passar uma encanação aqui que é pra pegar o "esgoto" dai da refinaria e jogar lá pra baixo, ali no mangue pegando o mar, ai vai poluir as águas e matar peixe, caranguejo, vai acabar com tudo. (Doméstica, Moradora nativa da comunidade há 42 anos).

É importante frisar que a maior parte dos moradores da comunidade é de analfabetos, o que intensifica o processo de vulnerabilidade dessa população, uma vez que dificulta o reconhecimento dos seus direitos frente aos interesses privados sobre suas terras. Corroborando essa constatação, Santos (2011) afirma que a incidência da pobreza é alta no município do qual a comunidade faz parte (Ipojuca), sendo de $62,83 \%$, o que proporciona um dos menores índices de desenvolvimento humano
(IDH), respectivamente 0,658 , e, consequentemente, eleva a taxa de analfabetismo, sendo de $28,4 \%$. no município.

Para Costa (2012), as atividades da refinaria, como o armazenamento, o transporte do petróleo e derivados e o refino, são responsáveis pela emissão de efluentes industriais, por emissões atmosféricas, pela poluição sonora e outras consequências desse processo produtivo, como também pelos vazamentos (Figura 3). Outro problema é o risco de grandes acidentes que podem ir além dos limites físicos da indústria, atingindo seu entorno com efeitos ecotoxicológicos de curto, médio e longo prazos, o que pode resultar numa série de graves eventos ambientais e sociais.

Sobre as interferências das atividades produtivas da refinaria na qualidade de vida da comunidade, há um profundo descontentamento, que vem se agravando nos últimos anos, conforme os seguintes relatos:

Entrevistado 3. Tinha uma água com o cheiro muito forte, os peixes da lagoa morreu tudo por causa dessa água aí, e esse cheiro de gás tava incomodando muito e dava dor de cabeça (Morador nativo da comunidade há 20 anos).

Entrevistado 4. O ruim é o cheiro que a gente sente $e$ às vezes fica mais forte à noite e a zuada da chama ali faz muito barulho também, a porta fica vibrando o gás chega pra cá (Morador nativo da comunidade há 53 anos).

Entrevistado 5. A refinaria tem afetado na saúde da minha família, dor de cabeça pela zuada e o gás afetou a saúde do meu filho (Morador nativo da comunidade há 22 anos).

Dessa forma, a instalação e a operação de grandes processos produtivos industriais apresentam ne- 


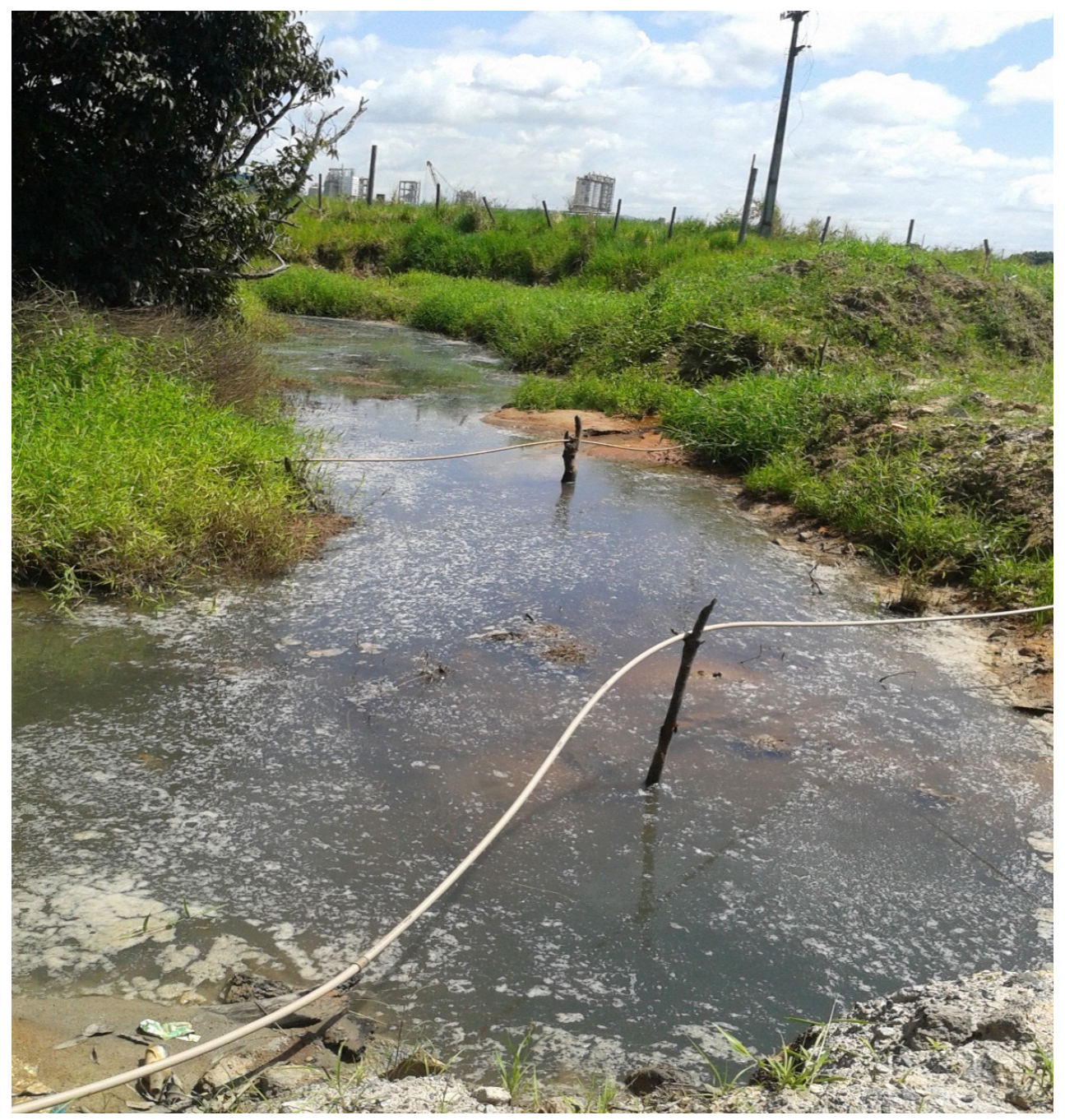

FIGURA 3 - Efluente industrial escoado para o manguezal. Distrito Industrial Portuário de Suape, Ipojuca - PE. FOTO: Stevam Gabriel, novembro de 2014.

xos causais com problemas de ordens socioambiental e de saúde das áreas e populações direta e indiretamente afetadas. Os problemas derivam de injustiças e conflitos ambientais decorrentes de disputas entre os interesses das comunidades locais e grupos sociais organizados, que são pautados pela premissa da justiça ambiental, e grandes corporações beneficiadas por atividades econômicas (Porto et al., 2013).

\subsection{A comunidade Ilha de Tatuoca}

Os moradores da Ilha de Tatuoca, em sua maioria, viviam basicamente da pesca artesanal (Silveira, 2010); porém, essa atividade vem diminuindo gradativamente devido ao processo de desterritorialização iniciado a partir da construção do estaleiro. Os moradores que viviam na ilha há 
centenas de anos foram retirados a partir de processos violentos, receberam pequenas indenizações e foram realocados numa vila na praia de Suape chamada Nova Tatuoca. A nova vila possui casas pequenas, com dois quartos, sala, cozinha, banheiro e um pequeno quintal sem espaço suficiente para plantio de árvores frutíferas e agricultura de subsistência, como eles eram acostumados a viver na ilha (Figura 4) (Domingues et al., 2014).

Durante gerações, as famílias sobreviveram da pesca artesanal, coleta de mariscos e crustáceos nos manguezais e colheita de alguns frutos tropicais comuns na região, como manga e caju. Santos \& Andrade (2013) afirmam que a comunidade transcende os limites terrestres e sua apropriação do espaço se dá mediante a articulação com aspectos relacionados ao uso, aos símbolos e ao conhecimento sobre as águas, constituindo-se em território marinho. A tradição em questão é intrínseca ao modo de produção e reprodução da vida em um espaço que extrapola a terra firme e é desenhado também pelas águas dos rios e do mar.

Devido à implantação dos Estaleiros Attântico Sul e Promar (Figuras 5a e 5b), uma série de impactos ambientais surgiu, tais como: desmatamento de vastas áreas, incluindo manguezais, redução na reprodução e na densidade de inúmeras espécies de crustáceos nativas dos manguezais, como siri, aratu e caranguejo, e alteração no ecossistema marinho e nos lençóis freáticos devido às dragagens para aprofundar o canal do porto (Domingues et al., 2014).

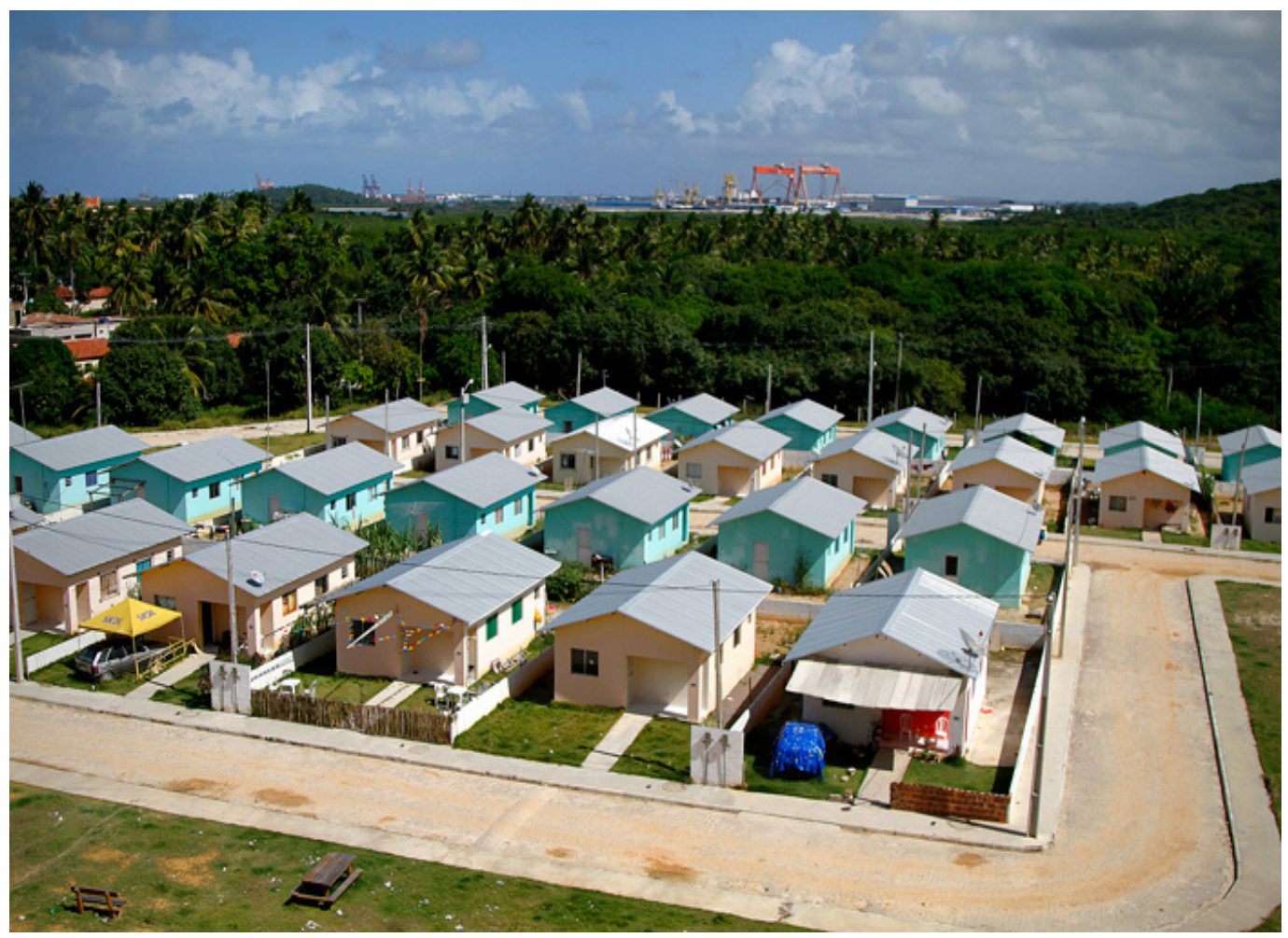

FIGURA 4 - Conjunto Habitacional Nova Tatuoca.

FONTE: Jornal do Comércio, 2015. 

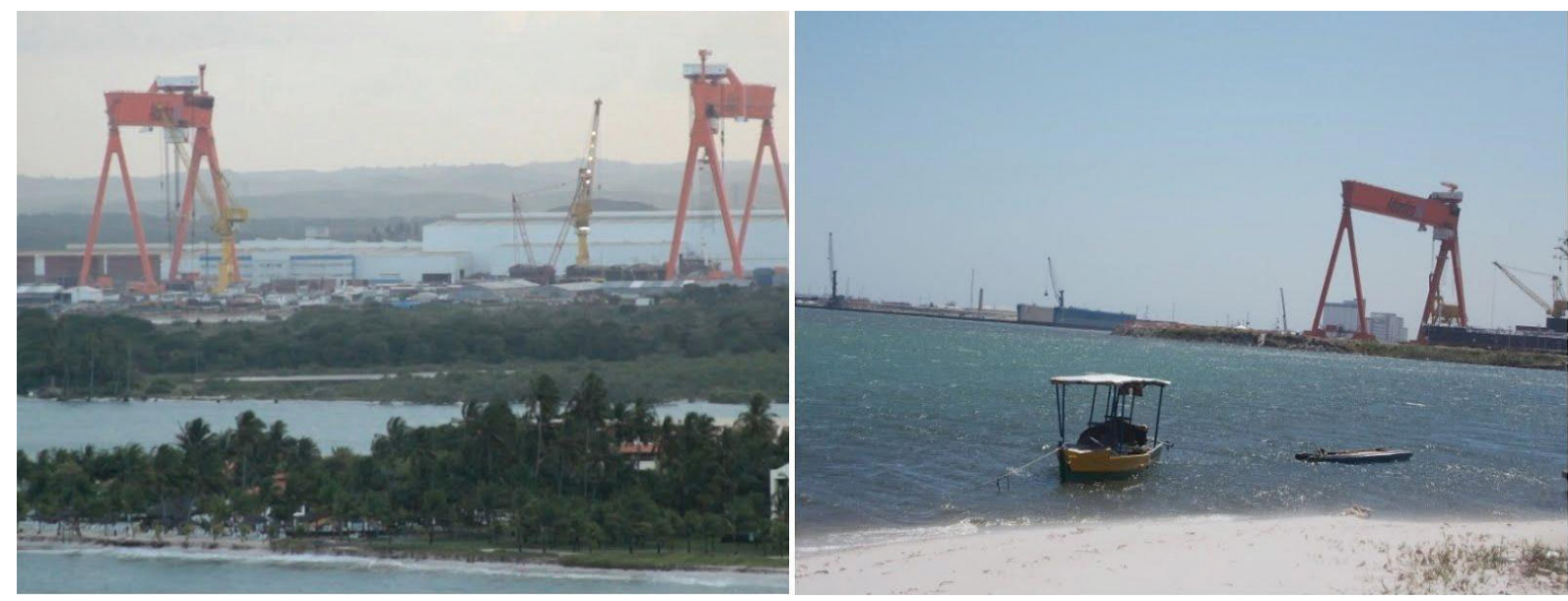

FIGURA 5 - Estaleiro Atlântico Sul (esquerda) e visto da Ilha de Tatuoca (direita).

FOTO: Domingues et al., 2014.

Relatos dos moradores denunciam o processo de vulnerabilização ocasionado pela implantação do Estaleiro:

Entrevistado 6. Não foi bom porque acabou com muita coisa do mangue, os peixes, muitos morreram, foi um desperdício (Pescadora e moradora nativa da comunidade).

Entrevistado 7. Quando tinha a dragagem apareciam muitas coisas mortas como: peixe e caranguejo, tudo que estava no mangue morria. Por semana tirava uns quinhentos a seiscentos reais e nem trabalhava muito, agora tem que trabalhar mais e tira menos (Doméstica, moradora nativa da comunidade há 30 anos).

Além dos impactos socioambientais ocasionados por esse empreendimento, parte da comunidade foi realocada para uma vila denominada Nova Vila Tatuoca (Figura 6). Essa mudança interferiu na reprodução social da comunidade, uma vez que os moradores, que em sua maioria são pescadores, não têm mais acesso aos recursos naturais antes dispostos próximos as suas antigas residências.
Entrevistado 8. Eu mesmo não gostei nada daqui, lá era mesmo que ouro, tinha tudo pra gente vender (frutas, marisco), a gente vivia daquilo ali, e aqui não tem nada.(Pescadora, Moradora nativa da comunidade há 35 anos)

Entrevistado 9. Lá em Tatuoca, mesmo que eu não trabalhasse tinha o mangue, agora depois da dragagem acabou-se tudo. Eu não sei dizer porque era meu pai que ficava com o dinheiro, mais dava pra gente viver direitinho (Doméstica, Moradora nativa da comunidade há 27 anos)

Após apresentados os principais fatores de vulnerabilização da comunidade em estudo, pode-se afirmar que o processo de industrialização atinge os moradores da Ilha de Tatuoca em variadas esferas de suas vidas: cultura, crença, identidade, saúde, moradia, segurança e também em seu trabalho e ambiente (Domingues et al., 2014). Diante desse contexto, Porto et al. (2013) afirmam que existem dois grandes grupos responsáveis por situações de injustiças ambientais: o primeiro se refere às atividades econômicas exploratórias e seus agentes, 


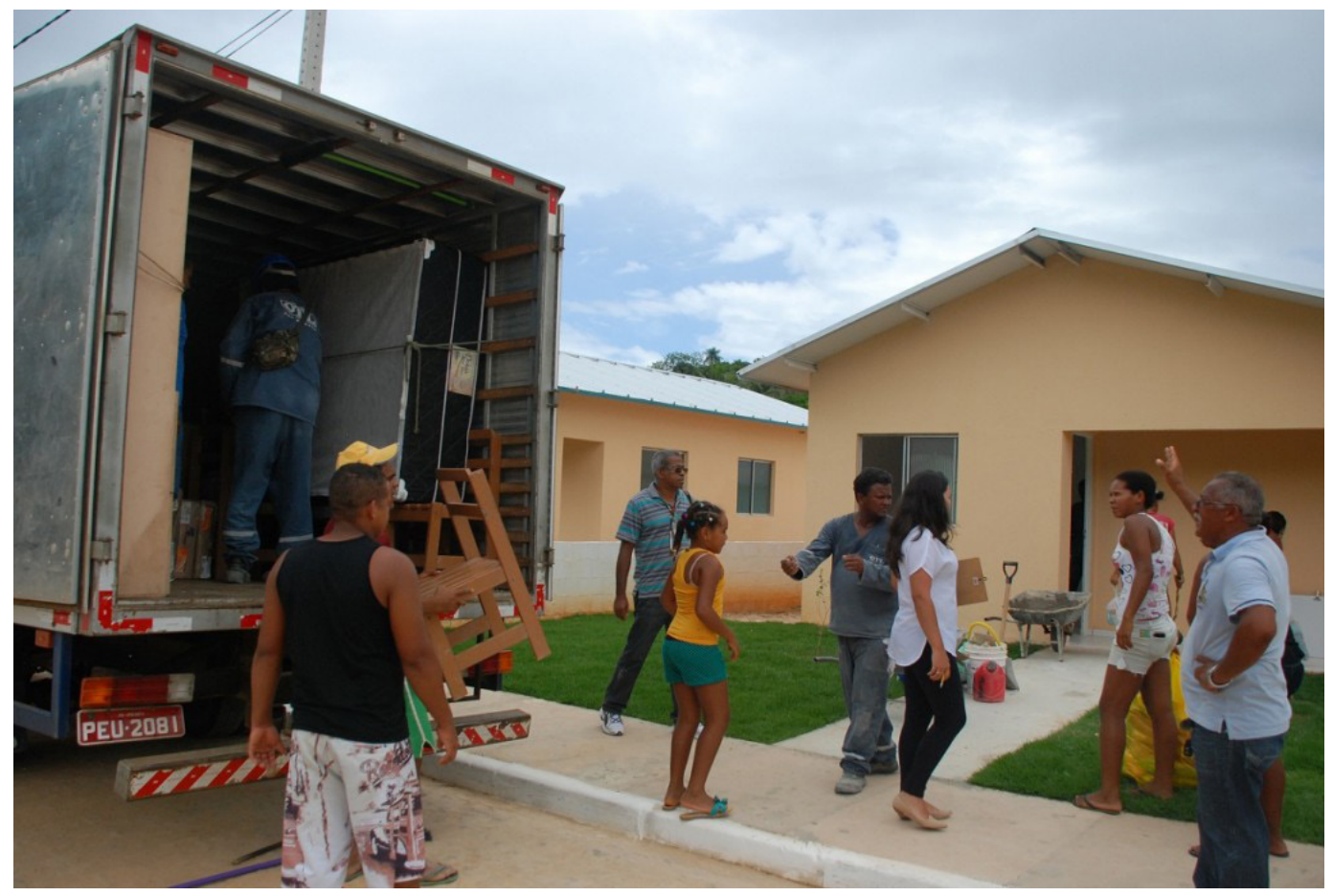

FIGURA 6 - Realocação dos moradores para a vila nova Tatuoca.

FONTE: Secretaria de Desenvolvimento Econômico de Pernambuco, 2014.

que sobrecarregam territórios e populações e interferem direta ou indiretamente em suas dinâmicas e modos de vida, neste caso, o CIPS. O segundo está associado à atuação ou à omissão do Estado, que apresenta debilidade em seus processos regulatórios e também estabelece coalizões com grandes corporações do setor econômico produtivo. Neste caso, a esfera política se faz responsável, uma vez que tem ciência desses acontecimentos, mas torna essa situação invisível, impossibilitando maiores repercussões sobre esses fatos e dando continuidade ao crescimento do Estado a qualquer custo.

Neste contexto, Schramm (2012) discute o fortalecimento da bioética da proteção como alternativa de resistência aos contextos adversos de conflitos de interesses e valores, dentre os quais as estruturas de poder e de dominação se manifestam e produzem situações de vulneração. Para o autor, existe o dever do Estado em assegurar direitos básicos e, por isso, mesmo em um contexto de Estado mínimo, o mesmo não pode se esquivar de proteger seus cidadãos.

\subsection{Conflitos socioambientais}

Little (2001) entende que um conflito pode ter várias dimensões, movimentos ou fenômenos complexos, mas começar a identificar os pontos críticos já é um progresso para o entendimento da dinâmica do conflito. Para ele, há três grandes tipos de conflitos: o primeiro está ligado ao controle sobre os recursos naturais, a pesca e o uso dos recursos florestais, entre outros; o segundo diz respeito aos 
conflitos em torno dos impactos (sociais ou ambientais) gerados pela ação humana, tais como a contaminação dos rios e do ar, o desmatamento, a construção de grandes barragens hidrelétricas, entre outros; o último está relacionado aos conflitos em torno dos valores e do modo de vida, isto é, conflitos envolvendo o uso da natureza cujo núcleo central reside num choque de valores ou ideologias. Essa tipologia serve, em parte, para tratar o foco central do conflito para melhor entendê-lo e resolvê-lo.

No que diz respeito ao entendimento e à solução dos conflitos socioambientais, Little (2001) argumenta que é necessário eliminar os meios que os originaram, além de que as resoluções das divergências existentes devem ocorrer de forma pacífica e consensual entre as partes. Em suma, os processos geradores de impactos ambientais devem cessar para que haja soluções de cunho socioambiental, porém, na realidade, isso é improvável que aconteça. Por isso, o autor fala em tratamento dos conflitos mais em torno da negociação e do consenso do que propriamente em uma resolução.

Com base no conceito exposto, pode-se afirmar que os conflitos socioambientais surgem quando a legalidade de determinadas formas de apropriação do espaço é colocada em xeque diante da ocorrência de efeitos indesejados de uma prática social sobre outra, ocasionando uma incompatibilidade entre determinadas práticas espaciais e pondo em questão a forma de distribuição do poder sobre os recursos do território (Acselrad et al., 2004).

Os meios predominantes de transmissão dos efeitos indesejáveis de determinadas práticas espaciais sobre outras caracterizam-se por seu caráter não mercantil (espaços de uso comum, como os corpos hídricos, o solo, a atmosfera e os ecossistemas). Esse fato se dá fundamentalmente pela constituição do capitalismo por meio da apropriação gratuita dos espaços de uso comum por meio das formas privadas de produção de mercadorias (Acselrad, 2010b).

A acumulação privada de riquezas ocorre principalmente por meio da produção de mercadorias vendáveis (aquelas que são dotadas e valor e, portanto, comercializadas) e dos produtos invendáveis (aqueles que não têm valor comercial), como os resíduos sólidos, líquidos e gasosos. Por não terem valor comercial ou não serem reaproveitáveis, esses rejeitos industriais são lançados em muitos casos nos espaços não mercantis, expondo as populações mais próximas do empreendimento e vulneráveis aos malefícios que provavelmente surgirão ao longo do tempo (Acselrad, 2010b).

Portanto, os conflitos socioambientais trazem à tona as diferentes formas de uso dos recursos naturais, particularmente, por atores sociais mais fortes, seja pela subtração de bens de uso comum das populações tradicionais que os utilizam, seja pelos impactos originados por determinados modos de produção que direcionam seus rejeitos aos bens não mercantis utilizados pelas populações tradicionais.

Com a chegada de grandes empresas nas comunidades Engenho Mercês e Ilha de Tatuoca, tais como a Refinaria Abreu e Lima e o Estaleiro Atlântico Sul, o que se constata há alguns anos é um enorme desrespeito às leis vigentes por parte da empresa gestora do complexo e a falta de responsabilidade socioambiental das empresas que lá se instalaram, responsáveis pela degradação ambiental desse território. Os reflexos desta política que considera a natureza um entrave ao crescimento econômico incluem a interrupção drástica dos modos de vida da população local, ferindo direitos adquiridos por posseiros, pescadores e agricultores familiares, expulsos de suas moradias, abandonados sem condições de trabalho ou qualquer assistência social digna. 
Segundo Rattner (2002, p. 78), o atual modelo de desenvolvimento econômico, apoiado em uma política liberal orientada para o mercado, não reduzirá os níveis de pobreza e exclusão, contribuindo para o aumento da desigualdade de distribuição de riqueza e para a diminuição de acesso a oportunidades de educação, saúde e emprego.

\section{Conclusão}

Diante os dados apresentados, identificou-se que as atividades produtivas dos empreendimentos no Complexo Industrial Portuário de Suape são as responsáveis diretas pelos processos de vulnerabilização socioambiental que atingem os moradores das comunidades Engenho Mercês e Ilha de Tatuoca, interferindo nas relações entre população e meio ambiente, determinando e/ou contribuindo para a existência de condições e situações de vulneração.

\section{Referências}

Acselrad, H. Justiça ambiental e construção social do risco. Desenvolvimento e Meio Ambiente, 5, 49-60, 2002. Disponível em: $<$ http://ojs.c3sl.ufpr.br/ojs/index.php/made/ article/view/22116/14480>

Acselrad, H. Vulnerabilidade, processos e relações. In: Ferreira, H. S.; Leite, J. R. M.; Boratti, L. V. (Orgs.). Estado de direito ambiental: tendências. 2 ed. Rio de Janeiro: Forense Universitária, 2010a.

Acselrad, H. Mediação e negociação de conflitos socioambientais. In: Anais do IX Encontro Temático da $4{ }^{\text {a }}$ Câmara da Coordenação e Revisão do Ministério Público Federal. Brasília, 2010b.

Acselrad, H. et al. A justiça ambiental e a dinâmica das lutas socioambientais no Brasil - uma introdução. In: Acselrad, H. et al. (Orgs.). Justiça ambiental e cidadania. Rio de Janeiro: Relume-Dumará, 2004. p. 10.
Nesse sentido, os processos de vulnerabilização têm seu ponto de partida na criação de políticas públicas pelo Estado que privilegiam a produção do espaço para grupos dominantes em detrimento das classes sociais menos favorecidas, trazendo a lume as contradições geradoras de desigualdades do desenvolvimento socioeconômico e ambiental no contexto do capitalismo e do Estado desenvolvimentista.

Dessa forma, as comunidades em questão seguem enfrentando conflitos de variadas dimensões, além de sofrer cotidianamente situações de violência, discriminação, exploração e abandono. Estas são populações que sofrem os impactos e os traumas das intervenções ambientais decorrentes de atividades industriais no seu território, portanto, são populações vulneradas, que vivenciam um processo de descaracterização socioambiental, cultural, política e econômica imposto por um modelo de "des-envolvimento" que não lhes garante sua reprodução social.

AGB - Associação dos Geógrafos Brasileiros. Relatório dos impactos socioambientais do Complexo Industrial Portuário de $A c ̧ u$. Rio de Janeiro. 2011. Disponível em: <http:// www.agb.org.br/documentos/Relatorio_dos_Impactos $\% 20$ socioambientais_do_Complexo_Portuario_do_Acu_ AGB_14092011.pdf > . Acesso em: 01 jul. 2015.

Alves, J. L. Suape e sua trajetória histórica: um olhar geográfico. Recife, Tese (Doutorado em Geografia) - Universidade Federal de Pernambuco, 2011.

Alves, S. G. Fatores de contaminação ambiental e riscos à saúde de populações localizadas no entorno do complexo industrial de Suape. In: Anais do V Congresso Brasileiro de Gestão Ambiental. Belo Horizonte/MG, 2014. Disponível em: <http://www.ibeas.org.br/congresso/Trabalhos2014/ XI-031.pdf $>$. Acesso em: 13 ago. 2015.

Cartier, R; Bracellos, C; Hubner, Cristiane; Porto, M. F. Vulnerabilidade social e risco ambiental: uma abordagem 
metodológica para avaliação de injustiça ambiental. Cadernos de Saúde Pública, 25(12), 2695-2704, 2009.

Costa, H. S. Complexo Industrial de Suape: os limites do desenvolvimento. Eco Agência: Núcleo de Ecojornalistas do Rio Grande do Sul - NEJ/RS, 2012. Disponível em: $<$ http://www.ecoagencia.com.br/index.php?open=noticias \&id=VZISXRIVONIYHZFRT1WNWJFbKVVVB1TP>. Acesso em 12 ago. 2014.

Costa, H. S. Complexo de Suape: 36 anos de uma triste história. Recife. 2014. Disponível em: <http://forumsuape. ning.com/profiles/blogs/complexo-de-suape-36-anos-de-uma-triste-historia>. Acesso em: 30 jun. 2015.

Domingues, R. C; Santos, M. O. S; Gurgel, I. G. D. A vulneração socioambiental advinda do Complexo Industrial Portuário de Suape: a perspectiva dos moradores da ilha de Tatuoca - Ipojuca-PE. In: Anais do $2^{\circ}$ Simpósio Brasileiro de Saúde, Ambiente e Desenvolvimento, Conflitos Territoriais e Saúde: ciência e movimentos sociais para justiça ambiental nas políticas públicas, Belo Horizonte, 2014. Disponível em: <http://www.sibsa.com.br/resources/anais/4/1404145748_ARQUIVO_Artigotatuoca-Rev. Tempus_Revisaoposparecer_resumido.pdf.>.

Fairclough, N. Analyzing discourse: Textual analysis for social research. London: Routledge, 2003.

Lakatos, E M. Fundamentos de metodologia científica. $5^{\circ}$. Ed. - São Paulo: Atlas 2003.

Little, P. E. Os conflitos socioambientais: um campo de estudo e de ação política. In: Bursztyn, M. (Org.). A difícil sustentabilidade: política energética e conflitos ambientais. Rio de Janeiro: Garamond Ltda., 2001.

Little, P. E. I Encontro Nacional de Populações Tradicionais: uma experiência na formulação de políticas públicas no Brasil. Brasília, DF, 2005. Disponível em: <http:// www.mds.gov.br/sobreoministerio/orgaoscolegiados/ orgaos-emdestaque/cnpct/arquivos/relatorios/PDF\%20\%20 I\%20Encontro\%20Nacional $\% 20 \mathrm{de} \% 20$ Comunidades $\% 20$ Tradicionais.pdf/view>.

Minayo, M. C. de S. O desafio do conhecimento: pesquisa qualitativa em saúde. 11. ed. São Paulo: Hucitec, 2008.

Moura, D. V. Justiça Ambiental: um instrumento de cidadania.Qualit@s Revista Eletrônica,9(1),2010.

Pérez, M. S.; Gonçalves, C. U. Desenvolvimento e conflito territorial: primeiras reflexões sobre as comunidades atin- gidas pelo complexo industrial portuário de Suape -PE, Brasil. Revista de Geografia, 29(2), 167-179, 2012. Disponível em: <http://www.revista.ufpe.br/revistageografia/ index.php/revista/article/view/691>.

Porto, M. F. de S. Uma ecologia política dos riscos: princípios para integrarmos o local e o global na promoção da saúde e da justiça ambiental. Rio de Janeiro: Fiocruz, 2007. $248 \mathrm{p}$.

Porto, M. F. de S. Complexidade, processos de vulnerabilização e Justiça Ambiental: um ensaio de epistemologia política. Revista Crítica de Ciências Sociais, 2011. Disponível em: <http://rccs.revues.org/133>.

Porto, M. F. de S. et. al. Injustiça ambiental e saúde no Brasil: o mapa de conflitos. Rio de Janeiro: Fiocruz, 2013.

Rapkiewicz, N. S; Alves, S. G; Santos, S. L. Engenho Mercês e Ilha de Tatuoca: exemplo de vulneração socioambiental. In: Anais do VI Congresso Brasileiro de Gestão Ambiental, Porto Alegre, 2015. v. 6. Disponível em: <www. ibeas.org.br/congresso/Trabalhos2015/XI-025.pdf>.

Rattner, H. Sobre o desenvolvimento sustentável. Mercosul e ALCA: o futuro incerto dos países sul-americanos. São Paulo: EdUSP, 2002.

Relatório de Impacto Ambiental da Refinaria do Nordeste. Localização da Refinaria do Nordeste (RENEST) e zoneamento da área do Complexo Industrial Portuário de Suape. 2005.

Rossini, R. E. A produção do novo espaço rural: pressupostos gerais para compreensão dos conflitos sociais no campo. Campo-Território: revista de geografia agrária, v. 4, n. 8, p. 5-28, ago. 2009.

Santos, J. O.; Andrade, M. O. Festa da Ouriçada e devoção a Santa Luzia na praia de Suape - PE. Horizonte, Dossiê: Religião, Biodiversidade e Território, 11(30), 545-571, 2013. Disponível em: $<$ http//periodicos. pucminas.br/index.php/horizonte/article/view/P.21755841.2013v11n30p545/5365>.

Santos, M. O. S dos. Análise crítica do discurso da mídia impressa sobre a saúde e o ambiente no contexto da instalação da refinaria de petróleo em Suape-PE. Recife, Dissertação (Mestrado Acadêmico em Saúde Pública) Centro de Pesquisas Aggeu Magalhães, Fundação Oswaldo Cruz, 2011. 
Schramm, F. R. Vulnerabilidade, vulneração, saúde pública e bioética da proteção: análise conceitual e aplicação. In: Taquette, S. R.; Caldas, C. P. (Orgs.). Ética e pesquisa com populações vulneráveis. Rio de Janeiro: Ed. EdUFRJ; 2012.

SEDUC - Secretaria de Desenvolvimento Econômico. Começa a mudança para Vila Nova Tatuoca. Disponível em: $<$ http://www.sdec.pe.gov.br/noticias/comeca-a-mudanca-de-moradores-para-vila-nova-tatuoca/>. Acesso em: 18 ago. 2015.

Silva, M. O. Saindo da invisibilidade: a Política Nacional de Povos e Comunidades Tradicionais. Inclusão Social, 2(2),
7-9, 2007. Disponível em: <http://revista.ibict.br/inclusao/ index.php/inclusao/article/viewFile/91/98>.

Silveira, K. A. Conflitos socioambientais e participação social no Complexo Industrial Portuário de Suape, Pernambuco. Recife: O Autor, 2010.

Trevas, J. Y. P. A importância da lei 8.630/93 para a modernização dos portos brasileiros: os casos de Pecém, Suape e Salvador. Recife, Dissertação (Mestrado em Economia) - Universidade Federal de Pernambuco, 2005.

Viégas, R. N. Desigualdade ambiental e "zonas de sacrificio”. PPGSA/IFCS - UFRJ. Rio de Janeiro, 2006. 